\title{
Medulloblastoma: A Common Pediatric Tumor: Experience of a Tertiary Care Cancer Center of Bangladesh.
}

\author{
Ghosh AK, ${ }^{1}$ Saha SK, ${ }^{2}$ Al -Amin ANM ${ }^{3}$, Gupta SPD ${ }^{4}$, Islam MJ ${ }^{5}$
}

Conflict of interest: There is no conflict of interest relevant to this paper to disclose.

Funding Agency : was not funded by any institute or any group.

Contribution of Authors : Principal Investigator- Dr. Ashis Kumar Ghosh

Manuscript preparation-Dr. Sanat Kumar Saha,

Data collection- Dr. Abu Naser Mohammad Al-Amin, Dr. Sudeshna Priyadarshini Das Gupta.

Editorial formatting- Dr. Md. Joynul Islam

Copyright: @2020bang.BJNS published by BSNS. This article is published under the creative commons CC-BY-NC license. This license permits use distribution (https://creativecommons. orgf/licences/by-nc/4-0/) reproduction in any medium, provided the original work is properly cited and is not used for commercial purposes.

Received: 03/08/2020

Accepted: 20/11/2020

\begin{abstract}
:
Background: Medulloblastoma is a common malignancy in the paediatric population, accounting for 25\% of all childhood brain tumors. The increasing magnitude of childhood cancer has become a threatening problem in developing countries like Bangladesh. But we have not enough data regarding the diseases of the children of Bangladesh. There is no literature available to shed light on Clinico-pathological types, diagnostic facilities and treatment patterns of this childhood cancer in our population. So this study is an opportunity to have experience about pediatric medulloblastoma of Bangladesh.
\end{abstract}

Methods: The study conducted from January 2014 to December 2018 at National Institute of Cancer Research and Hospital (NICRH). Data are collected from admitted children aged under 18 years in the department of Pa ediatric Hematology and Oncology (PHO) and confirmed by histopathology and/or immunohistochemistry after collection of tissues from pathological lab. The data were obtained from statistical analysis by PSPP software

Results: During 2014 to 2018 total diagnosed cases of childhood meduloblastoma were 57 but data were analyzed from only 52 patients. Male female ratio was 1.9:1. Median age of our patients was 6.12 years. Most common clinical features at preoperative assessment were vomiting, headache, fever, convulsion, eye/vision involvement. Hydrocephalus was Present in 48 (92\%) cases. Radiologically distal metastasis were found in 2 (3.85\%) cases.

Tumor resection was performed in all patients and total removal in 56.80\% (N-25), gross total removal 25\% ( $N-11)$, and partial removal $18.20 \%(N-8)$ and in 8 cases resection type were not elicited. Pathological grading were recorded in 52 patients, where all were Grade-IV (100\%). Within 22 months of follow up time absconded patients were $44.4 \%$, partially treated cases are $9.6 \%$ with high death rate (23\%). Regular treated cases with good outcome were $23 \%$.

Conclusions: Medulloblastoma is a challenging condition for neurosurgeon, radiotherapist and oncologists of Bangladesh. We have to reduce the abandon cases; review the risk stratification by using molecular profile and enhance the support service to improve the survival rate.

$R T$ - radiotherapy, CT-Chemotherapy, UB-Urinary Bladder.

All patients underwent preoperative Computed tomography (CT) or Magnetic resonance imaging (MRI) of head (Fig. 1) But 90.4\% (N-47) MRI/CT reports were able to given a proposed diagnosis like medulloblastoma or ependymoma, 5.7\% ( $N$-3) diagnosed as space occupying lesion (SOL) and 2 (3.9\%) case didn't make any remarks regarding the brain lesion (Table-3).Tumors arise from midline (Vermis) were $71.15 \%$ (N-37) and from hemisphere were $28.85 \%(N-15)$.

Bang. J Neurosurgery 2021; 10(2): 154-162

1. Dr. Ashis Kumar Ghosh, Assistant Professor, Department of Paediatric Haematology and Oncology, National Institute of Cancer Research and Hospital

2. Dr. Sanat Kumar Saha, Assistant Professor, Department of Neurosurgery, Sir Salimullah Medical College \& Mitford Hospital.

3. Dr. Abu Naser Mohammad Al-Amin, Assistant Professor, Department of Paediatric Haematology and Oncology, National Institute of Cancer Research and Hospital

4. Dr. Sudeshna Priyadarshini Das Gupta, Assistant Professor, Sapporo Dental College and Hospital

5. Dr. Md. Joynul Islam, Associate Professor, Department of Clinical Neurosurgery, National Institute of Neuroscience Hospital Address of Correspondence: Dr. Ashis Kumar Ghosh, Assistant Professor, Department of Paediatric Haematology and Oncology, National Institute of Cancer Research and Hospital, Mobile: +8801712685509 Email. ashiskumarghosh@gmail.com 


\section{Introduction:}

Medulloblastoma is a common malignancy in the paediatric population, accounting for $25 \%$ of all childhood brain tumors. ${ }^{1}$ and accounts for approximately $30-40 \%$ of childhood posterior fossa tumors. ${ }^{2,3}$ It is an embryonal tumor, located almost exclusively in the cerebellum, with an inherent tendency to metastasize via cerebrospinal fluid (CSF) pathways. While some genetic disorders (i.e.Gorlin syndrome, Turcot syndrome, Li-Fraumeni syndrome) are associated with an increased risk of medulloblastoma, for most patients the etiology is unknown. ${ }^{4}$

Medulloblastoma is referred to now as a primitive neuro-ectodermal tumor. The median age of diagnosis is 5 years, with $80 \%$ of cases being diagnosed in the first 15 years. But in Bangladesh, we have no population-based cancer registry which is necessary for determine the cancer burden of paediatric population and till now there are no study on paediatric medulloblastoma in our country. More over we have not enough knowledge about the presentations of the tumor, staging, surgical intervention, diagnostic accuracy and present treatment options available in Bangladesh of this feared disease.

Currently, risk stratification for patients is based on clinical features including age, degree of surgical resection and presence or absence of metastasis. ${ }^{5}$ Standard of care treatment for children ${ }^{3} 3$ years entails surgical resection, craniospinal irradiation (CSI) and chemotherapy that has resulted in an overall cure rate of $\sim 70-75 \% .^{5,6}$ However, most survivors are left with long-term disabilities secondary to the disease and treatment. ${ }^{7}$ In recent years, there has been progress in understanding the heterogeneity of medulloblastoma, which has led to further refinements of risk stratification and prognosis ${ }^{8.9}$

Internationally the incidence of medulloblastoma is estimated to be 0.7 per 100000 children ${ }^{10}$ But lack of population-base cancer registry, we have no data regarding the burden of the diseases of Bangladesh.

So this prospective study was carried out in our department $(\mathrm{PHO})$ to study the clinical features, radiological interpretation, diagnostic challenge, type of surgical intervention in the posterior fossa, finally current and future treatment strategies of medulloblastoma.
Materials and Methods:

This study was conducted in the Department of Paediatric Hematology and Oncology (PHO), NICRH during year 2014 to 2018. Demographic variables, clinical variables, radiological findings with respect to age, sex, signs and symptoms, location of tumor, extent of surgical resection, histopathology type, follow-up period and outcomes were recorded. Clinical features were collected from statement of patients/ parents and records of general practitioner. Biopsy tissues were collected from respected pathological lab and confirmed by histology and/or immunohistochemistry.

In our department $(\mathrm{PHO})$ treatment protocols are based on risk stratification (Table-1), which took into account age at presentation, residual disease [residual tumor at the primary site after surgery measured by postoperative gadolinium- enhanced magnetic resonance imaging (MRI)] or according to operation notes mentioned by neurosurgeons. Dissemination of disease at the time of diagnosis was evaluated by combination of full spine imaging and CSF (Lumbar cerebrospinal fluid) study.

\section{Table-I}

Risk classification of medulloblastoma.

\begin{tabular}{ll}
\hline Risk classification & Characteristics \\
\hline Average-risk disease & $>3$ years or 3 years of age, \\
& $<1.5 \mathrm{~cm}^{2}$ postoperative \\
& residual tumor and the \\
& absence of metastatic disease \\
& $<3$ years or 3 years of age, \\
High-risk disease & $>1.5 \mathrm{~cm}^{2}$ postoperative \\
& residual tumor and/or the \\
& presence of metastatic disease \\
\hline
\end{tabular}

\section{Results:}

Total 2242 child with childhood cancer was admitted in the department of PHO during 2014 to 2018 and 260 (11.59\%) were Central Nervous System (CNS) tumors. Among them diagnosed cases of childhood medulloblastoma were 57 and we have collected data from only 52 patients. Male female ratio was 1.9:1( $\mathrm{M}=34, \mathrm{~F}-18)$. Median Age of our patients was 6.12 years, range 2-14 years. Median duration of start of treatment after start of symptom was 7.1 months (Range $0.5-60$ months). Age of 7 patients were $£ 3$ years. Most common clinical features are listed in table-2. 


\section{Table-II}

Common clinical features of 52 patients.

\begin{tabular}{lll}
\hline Signs and Symptoms & Results(N-52) & Remarks \\
\hline Vomiting & $45(86.54 \%)$ & \\
Headache & $41(78.85 \%)$ & \\
Fever & $21(40.38 \%)$ & \\
Convulsion & $10(19.23 \%)$ & Visual blurring and or diplopia \\
Eye/vision involvement & $21(40.38 \%)$ & \\
UB/Bowel involvement & $2(3.85 \%)$ & \\
Gait abnormality /Limb paresis & a) Limb-21(40.38\%) & \\
& b) Facial - $01(1.92 \%)$ & \\
Unconsciousness & $6(11.54 \%)$ & \\
Tilting of Head & $2(3.85 \%)$ & Patients done surgery \\
Enlarge head size & $12(23 \%)$ & previously but didn't take RT or CT \\
Recurrence cases & $3(5.76 \%)$ & \\
\hline
\end{tabular}
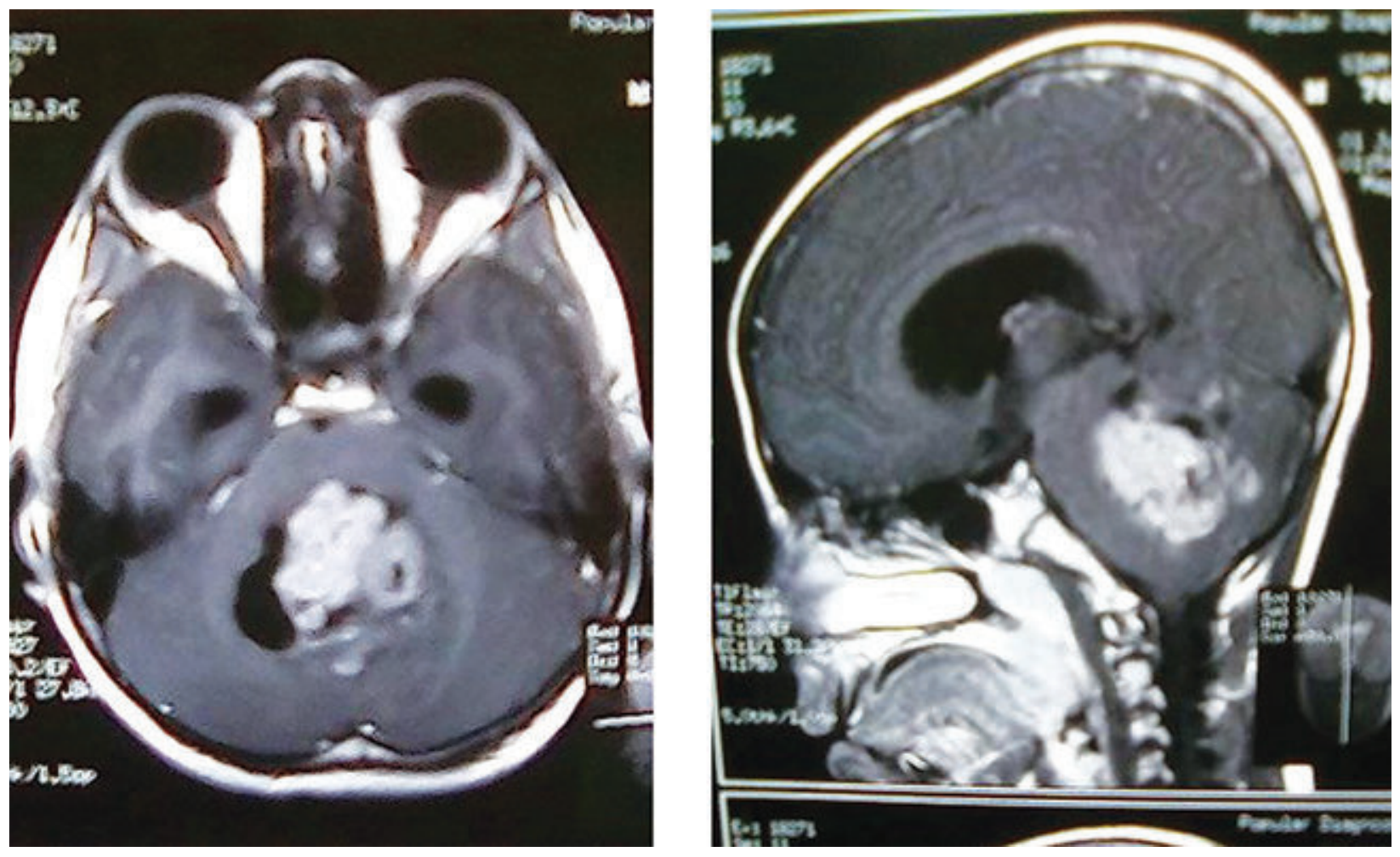

Fig.-1: Brain magnetic resonance of Axial and sagittal images showing Medulloblastoma of a 8 years boy. 
Table-III

Investigations and its findings

\begin{tabular}{lll}
\hline Investigation & Results & Remarks \\
\hline MRI/CT scan done & $100 \%$ &
\end{tabular}

Radiological (MRI/CT Scan) evaluation:

a). Proposed diagnosis (like Medulloblastoma,ependymoma )

b). Non specific diagnosis like space occupying lesion (SOL)

c). No comments

Hydrocephalus

Radiologically metastasis

Tumor location a). $90.4 \%(\mathrm{~N}-47)$

b). $5.7 \%(\mathrm{~N}-3)$

c). $3.9 \%(\mathrm{~N}-2)$

a) Present $92 \%(\mathrm{~N}-48)$

b) Absent $8 \%(\mathrm{~N}-4)$
Liver and Spinal cord

Vermis $71.15 \%(\mathrm{~N}-37)$

Hemisphere $28.85 \%,(\mathrm{~N}-15)$

Tumor resection was performed in all patients but we were able to analyzed 44 cases where total removal were in 25 patients ( $\mathrm{N}-44,56.82 \%$ ), gross total removal were in 11 patients $(\mathrm{N}-44,25 \%)$, partial removal were in 8 patients $(\mathrm{N}-44,18.18 \%)$ but resection type could not elicited in 8 cases $(15.38 \%, \mathrm{~N}-52)$ from operation notes or post operative MRI. (Fig 2)

Medulloblastomas are universally grade IV ${ }^{11}$ because of their aggressive nature, with malignant cytologic features, rapid disease evolution, and a fatal outcome if not treated with multimodal therapies. These tumors

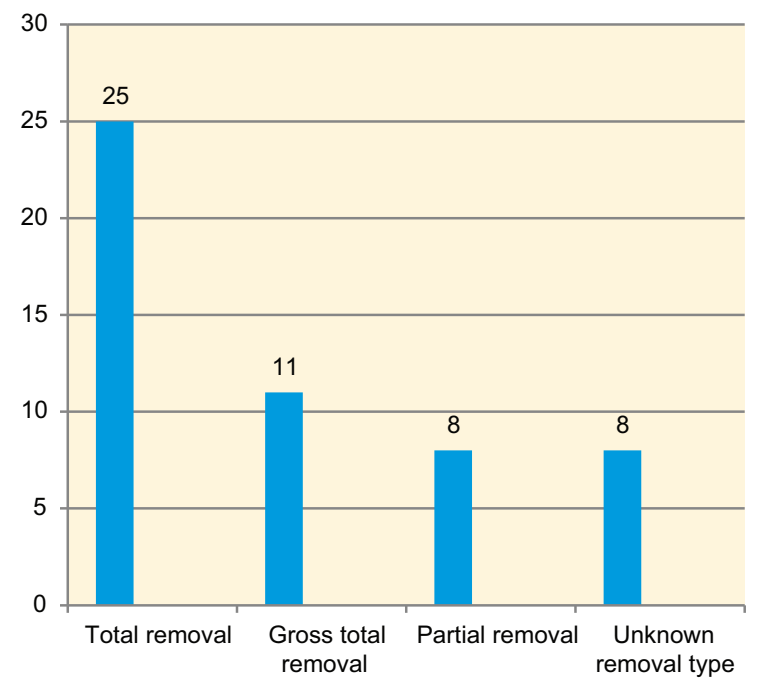

Fig.-2: Types of removal of 52 Medulloblastoma show either classic histologic features or histologic features of one of the variant nonclassic subtypes: desmoplastic medulloblastoma, medulloblastoma with extensive nodularity, or large cell (LC) or anaplastic medulloblastoma.

In our study classical medulloblastoma (MB) in 51 cases (98\%), Desmoplastic/Nodular MB -2 \% (N-1), there was no large cell or anaplastic cell variant of Medulloblastoma. Provisional diagnosis of medulloblastoma by MRI/CT of 47 cases were evaluated by tissue biopsy and $38(73 \%)$ cases were same as MRI/CT diagnosis. Only 9 patients were evaluated by immunohistochemistry $(\mathrm{IHC})$ and all IHC reports correlated tissue biopsy reports. Cerebrospinal Fluid (CSF) was examined of 14 patients for malignant cells, only 5 cases $(35.71 \%$ ) were positive for malignant cells. Medulloblastoma were classified according to the risk stratification system into two groups (Table4). In our study post surgical MRI were not done regularly or in timely. So for assessment of residual tumor, we have to rely on surgical note also, mentioned by neurosurgeon. In our study high-risk group and average-risk patients were 38 (73\%) and 14 (27\%) respectively.

Operative complications included gait unsteadiness in 32 cases $(61.5 \%)$. 
Table-IV

Common investigations and findings

\begin{tabular}{|c|c|c|}
\hline Surgical and Pathological events & Result & Remarks \\
\hline Tumor Removal & $\begin{array}{l}\text { a) Total removal } 56.82 \%(25 / 44) \\
\text { b) Gross Total Removal } 25 \%(11 / 44) \\
\text { c) Partial Removal } 18.18 \%(8 / 44) \\
\text { d) Not mentioned in } 15.38 \%(8 / 52) \\
\text { pathological reports. }\end{array}$ & $\begin{array}{l}\text { For result }(d), \% \text { was calculated } \\
\text { from total } 52 \text { cases }\end{array}$ \\
\hline Pathological Grading & Grade-IV-52 (100\%). & \\
\hline $\begin{array}{l}\text { Pathological Types } \\
\text { (Total number }=52 \text { ) }\end{array}$ & $\begin{array}{l}\text { a) classical MB -98 \% (N-51) } \\
\text { b) Desmoplastic/Nodular MB -2\% } \\
\text { (N-1) } \\
\text { c)Anaplastic MB - } 0 \% \\
\text { d) Large cell MB -0 \% } \\
\text { e) MBEN }-0 \%\end{array}$ & $\begin{array}{l}\text { MBEN- } \\
\text { Medulloblastoma } \\
\text { with extensive } \\
\text { nodularity. }\end{array}$ \\
\hline MRI/CT scan evaluation sensitivity & $73 \%(\mathrm{~N}-38)$ correlated with tissue biopsy & \\
\hline $\begin{array}{l}\text { Tissue biopsy and } \\
\text { IHC sensitivity. } \\
\text { Shunt }\end{array}$ & $\begin{array}{l}100 \%((\mathrm{~N}-9) \mathrm{IHC} \text { reports are same as } \\
\text { biopsy reports. } \\
32(61.50 \%)\end{array}$ & \\
\hline $\begin{array}{l}\text { CSF study blast cell } \\
\text { positive }(\mathrm{N}-14)\end{array}$ & $5(35.71 \%)$ & $\begin{array}{l}\text { Total CSF study } \\
\text { done in } 14 \text { cases }\end{array}$ \\
\hline High-risk & $38(73 \%)$ & \\
\hline Average-risk & $14(27 \%)$ & \\
\hline
\end{tabular}

Treatment and outcomes are described in Table 5. Our follow up (F/U) time is only 22 months. Due to various causes a large number of patients $(44.4 \%)$ cannot afford treatment cost. Partially treated cases are significant in number $(9.6 \%)$ with high death rate $(23 \%)$.

Table-V

Treatment and outcome of Medulloblastoma

\begin{tabular}{|c|c|c|c|}
\hline$\overline{S I . n o}$ & Follow-up status & Quantity & Remarks \\
\hline & Life $(32.6 \%)$ & & \\
\hline \multirow[t]{2}{*}{1.} & $\begin{array}{l}\text { 1. Partially treated } \\
\text { cases }(9.6 \%)\end{array}$ & $\begin{array}{l}\text { i) Surgery with Homeopathy-1 } \\
\text { ii) Surgery + only RT- } 3 \\
\text { iii) Treated in PHO+ India-1 }\end{array}$ & $\begin{array}{l}\text { These patient do } \\
\text { not come } \\
\text { for regular F/U }\end{array}$ \\
\hline & $\begin{array}{l}\text { 2. Fully Treated cases } \\
\text { (Surgery+RT+CT)/ On } \\
\text { Follow up }(23 \%)\end{array}$ & 12 patients & \\
\hline 2. & Death $(23 \%)$ & $\begin{array}{l}\text { a) During RT/CT- } 4 \\
\text { b)After the end of treatment- } 3 \\
\text { c) recurrence cases- } 5\end{array}$ & \\
\hline 3. & No Treatment/Abandoned (44.4\%) & 23 patients & \\
\hline 4. & Median Follow-up period & 22 months & \\
\hline
\end{tabular}




\section{Discussion:}

Because of the lack of information on paediatric brain tumors in Bangladesh, especially on medulloblastoma, this study focused basically on clinical presentation, diagnostic tools, pathological types, surgical intervention and outcome of childood medulloblastoma.

Medulloblastomas( MB) are considered high-grade embryonal tumors based on histology and cell of origin. They can occur in both children and adults, although greater than $70 \%$ of cases are found in children less than 18 years old. ${ }^{12}$ Our selected patients age were less than 18 years. From 2014 to 2018, total childhood CNS tumors treated in our department (PHO) were 260 and medulloblastoma were $57(11.59 \%)$ in number but we collected data from 52 patients. Louis et al estimated that medulloblastoma is the accounts for $15-20 \%$ of all CNS tumors and it is more frequent in male ( 65\%) and median age of onset is approximately 7 years. ${ }^{13}$ Percentage of medulloblatoma in our study is a bit less $(11.59 \%)$ than Louis et al but median age of onset (6.12 years) and sex ratio (M:F $1.9: 1)$ is nearer to other studies.

Patients of medulloblastoma often harbor a different type of embryonal tumor. Rorke et al mentioned that approximately $15 \%$ to $20 \%$ of infants who would previously have been diagnosed as having medulloblastoma, harbor a different embryonal tumor, the atypical teratoid/rhabdoid tumors ${ }^{14}$ but none of our patients suffered from any different tumor.

Dorner et al maintioned average time from symptom onset to diagnosis ranges from 2 to 6 months. ${ }^{15,16}$ but in our study, median duration from start of symptom to start of treatment/diagnosis was 7.1 months (Range 0.5 -60 months). This data more or less correlate with previous studies in our Institute.

Patients with medulloblastoma commonly present with signs and symptoms of cerebellar dysfunction and increased intracranial pressure (ICP). Common signs and symptoms of increased ICP such as headaches (worse on lying down and upon waking up in the morning), nausea, vomiting, gait changes, sixth cranial nerve palsy (caused by hydrocephalus and hence a false localizing sign), diplopia, nystagmus and papilledema. Medulloblastoma can also present acutely with a severe alteration in consciousness and even coma. This is usually due to hemorrhage into the tumor, and rapid tumor expansion with acute hydrocephalus and/or compression of the brainstem. ${ }^{17}$ In our findings most common symptoms were vomiting (86.54\%), headache(78.85\%), Eye/vision involvement i.e diplopia, nystagmus and papilledema (40.38\%),Fever (40.38\%), gait change (40.38\%), facial paralysis was in one patient, unconsciousness( $11.54 \%)$ and macrocephaly (23\%). This study more or less correlate with the findings of study of Estelles et al findings where vomiting $79.4 \%$, headaches $71.4 \%$, gait change $36.5 \%{ }^{18}$

Due to its wide availability, computed tomography (CT) is often the first imaging study performed in children presenting neurological symptoms which suggest a brain tumor. Nevertheless, magnetic resonance imaging (MRI) is a superior method, due to its greater sensitivity compared to CT and the fact that it allows for a more precise assessment of the tumor's size, location and neoplastic subarachnoid spread. ${ }^{19}$ Our cent percent patients were evaluated by CT scan or MRI at first. But in all cases, CT/MRI could not able to confirm the tumor type. Only $90.4 \%(\mathrm{~N}-47) \mathrm{MRI} / \mathrm{CT}$ reports were able to given a proposed diagnosis like Medulloblastoma, Ependymoma etc, 5.7\% (N-3) diagnosed as non specific tumor i.e. space occupying lesion (SOL) and in 2 (3.9\%) cases didn't make any remarks regarding the brain lesion. In the study Hydrocephalus were found in $92 \%$ (N-48) cases, which correlate with Koral et al. who said that as the lesions grow, there is anterior displacement and compression of the fourth ventricle, which often leads to obstructive hydrocephalus in approximately $90 \%$ of cases if uncompensated. ${ }^{20}$ Subarachnoidal spreading occurs more frequently along the normal CSF flow, hence the most common location of metastases is along the posterior surface of the spinal cord. ${ }^{21,22}$ We have identified metastasis in spinal cord for one patient, one in liver. Malignant cells for CSF were positive for 5 (35.71\%) cases. But Fouladi M et al maintioned, the tumor tends to metastasize through the subarachnoid space. Thirty-two percent of patients showed cerebrospinal fluid (CSF) dissemination at diagnosis. ${ }^{23}$ In our series tumors arise from midline (Vermis) were in 37 children ( $71.15 \%$ ) and from hemisphere were in 15 cases $(28.85 \%)$ ). This data correlate with data of Nalita $\mathrm{N}$ et al study where tumors from vermis (midline) were $78.2 \%$ and from hemisphere were $21.8 \%{ }^{24}$

Radiological diagnosis of metastasis were only $3.85 \%$, which is far different from Estelles et al ${ }^{18}$ study 
where Twenty-one Patients (32\%) had dissemination at the time of diagnosis, which was detected by radiology.

In the management of medulloblastoma, complete resection should be performed if possible as several studies have correlated outcome with extent of resection and amount of residual tumor. ${ }^{25}$ Kumar et al reported in their study gross total resection in $8(15 \%)$ patients, near total resection in $34(64 \%)$ patients and subtotal resection in $11(21 \%)$ patients. ${ }^{26}$ But in our study the data is a bit different, that is total removal of tumor were in 25 patients $(56.82 \%)$, gross total removal were in 11 patients $(25 \%)$, partial removal were in 8 patients $(18.18 \%)$ and reports about the extent of surgical removal of 8 patients $(15.38 \%, \mathrm{~N}-52)$ were not mentioned in surgical notes or post surgical MRI.

Lee et al said most patients have resolution of hydrocephalus following tumor resection, but approximately $40 \%$ will require a ventriculoperitoneal shunt within 4 weeks of resection. ${ }^{27}$ In our finding shunt requirement is more than Lee et al. In our series shunt requirement during tumor operation were $61.50 \%$, which is nearer to the study of Kumar et al $(60 \%){ }^{26}$

Medulloblastomas are undifferentiated embryonal neuroepithelial tumors of the cerebellum arising predominantly from the cerebellar vermis. The cell of origin and the exact histological classification of this highly malignant tumor are still controversial. ${ }^{28}$ However Estelles et reported histologically classic $\mathrm{MB}$ is $71.4 \%$ and Nodular MB is $25.4 \%{ }^{18}$ But in our calculation the classical type of Grade-IV medulloblastoma were $98 \%$ (N-51), Desmoplastic/ Nodular MB -2\% (N-1), there was no large cell or anaplastic cell variant of medulloblastoma. Findings of Kumar et al (classical MB -90.3\%,Desmoplastic medulloblastoma $3.2 \%$ ) are more nearer to our data. ${ }^{26}$

We evaluate the sensitivity of CT/ MRI diagnosis of medulloblastoma. We considered 47 cases that were diagnosed as medulloblastoma by CT/MRI and followed the biopsy reports of those patients. Biopsy results yielded $73 \%(\mathrm{~N}-38)$ diagnosis were same as $\mathrm{MRI} / \mathrm{CT}$ recommendation. Tissue from 9 patients that diagnosed as medulloblastoma by biopsy were done immunohistochemistry and found all IHC reports correlated tissue biopsy reports.

However, there is a disparity in survival rates in low to middle income countries-ranging from $33 \%$ to $73 \% .{ }^{29,30}$ Treatment refusal or abandonment (44.4\%) is a major problem for our country. Partially treated cases are significant in number $(9.6 \%)$ with high death rate ( $23 \%$ within 22 months of $F / U)$. Our follow up time is only 22 months and only $23 \%$ patients are on follow up with expected health. Abandoned from child cancer treatment is a common problem in low income countries Most common reasons were financial difficulties. A study in Kenya found $54 \%$ children with cancer were abandoned from treatment. ${ }^{31}$ Our experience $(44.4 \%)$ is less in number than Kenya.

\section{Future of Medulloblastoma Management}

The current clinical risk stratification for children with medulloblastoma as listed in Table-1 fails to recognize the biologic heterogeneity of this disease and has not been useful in accurately predicting outcome with $20 \%$ of average-risk patients failing risk-adapted cytotoxic therapy and $50-70 \%$ of those with high-risk disease doing well with the same approach. ${ }^{32}$ There are four medulloblastoma molecular groups - WNT-activated, $\mathrm{SHH}$-activated, group 3, and group 4 and addressing these clinical and molecular features of medulloblastoma patients will get more benefit from the new risk-adapted therapeutic approach. Ongoing clinical trial after performing molecular analysis of tumors are started in developed countries like USA. The genomic era of medulloblastoma is fast ushering in a need for a more personalized approach to treating this disease by using molecular information from each patient's tumor and deciding on best combination of targeted therapies to produce sustained tumor control. It should be remembered that despite the rapid advances made in the last few years understanding the molecular landscape of medulloblastoma, surgery and cytotoxic therapy are still the mainstay of treatment for this aggressive tumor.

\section{Conclusion.}

Childhood medulloblastomas remain a challenging oncologic condition specially for Bangladesh where a large number of children cannot afford treatment expenses and abandoned from treatment. Cancer care in Bangladesh depends entirely on a patient's socioeconomic status. This situation should be change. In this moment our main goal is to improve the support of average-risk patients with current treatment regimens and maintain adequate survival. For patients with high-risk and recurrent disease, survival remains poor. But advances in understanding molecular profile and associated clinical outcome will eventually lead to better risk stratification and enable 
oncologists to give better treatment plan for each individual patient. Therapy for childhood medulloblastoma requires a delicate balance between the need to intensify therapy and the desire to reduce toxicity to have a better quality of life.

\section{Source of Support: Nil}

\section{Reference:}

1. Rorke LB. The cerebellar medulloblastoma and its relationship to primitive neuroectodermal tumors. J Neuropathol Exp Neurol 1983;42:1-15.

2. Kun LE, MacDonald S, Tarbell NJ. Tumors of the Posterior Fossa and the Spinal Canal. In: Halperin EC, Constine LS, Tarbell NJ, Kun LE (eds.). Pediatric Radiation Oncology, 5th edition, Williams and Wilkins, Philadelphia 2011;53-84.

3. Tortori-Donati P, Fondelli MP, Rossi A et al. Medulloblastoma in children: CT and MRI findings. Neuroradiology 1996;38(4):352-9.

4. Villani A, Malkin D, Tabori U. Syndromes predisposing to pediatric central nervous system tumors: lessons learned and new promises. Curr Neurol Neurosci Rep 2012;12(2):153-64

5. Gajjar A, Chintagumpala M, Ashley D, et al. Risk-adapted craniospinal radiotherapy followed by high-dose chemotherapy and stem-cell rescue in children with newly diagnosed medulloblastoma (St Jude Medulloblastoma-96): long-term results from a prospective, multicentre trial. Lancet Oncol 2006;7(10):813-20 .

6. Packer RJ, Zhou T, Holmes E, et al. Survival and secondary tumors in children with medulloblastoma receiving radiotherapy and adjuvant chemotherapy: results of Children's Oncology Group trial A9961. Neuro Oncol 2013;15(1):97-103 .

7. Edelstein K, Spiegler BJ, Fung S, et al. Early aging in adult survivors of childhood medulloblastoma: long-term neurocognitive, functional, and physical outcomes. Neuro Oncol 2011;13(5):536-45

8. Kool M, Korshunov A, Remke M, et al. Molecular subgroups of medulloblastoma: an international metaanalysis of transcriptome, genetic aberrations, and clinical data of WNT, SHH, Group 3, and Group 4 medulloblastomas. Acta Neuropathol 2012;123(4):473-8

9. Northcott PA, Korshunov A, Witt $\mathrm{H}$, et al. Medulloblastoma comprises four distinct molecular variants. J Clin Oncol 2011;29(11):1408-14

10. McKean-Cowdin R, Razavi P, Barrington-Trimis J, et al. Trends in childhood brain tumor incidence, 1973-2009. J Neurooncol 2013;115(2):153-160.

11. Giangaspero F, Eberhart CG, Haapasalo $\mathrm{H}$, et al. Medulloblastoma. In: Louis DN, Ohgaki H, Wiestler OD, Cavenee WK, eds. WHO classification of tumours of the central nervous system. Lyon, France: IARC Press 2007:132-140

12. Curran EK, Sainani KL, Le GM, et al. Gender affects survival for medulloblastoma only in older children and adults: a study from the surveillance epidemiology and end results registry. Pediatr Blood Cancer 2009;52(1):60-64.

13. Louis David N , Hiroko Ohgaki. WHO Classification of Tumours of the Central Nervous System; 2007

14. Rorke LB, Packer RJ, Biegel JA. Central nervous system atypical teratoid/ rhabdoidtumorsofinfancy and childhood: definitionofanentity. JNeurosurg 1996;85(1):56-65.

15. Dörner L, Fritsch MJ, Stark AM, et al. Posterior fossa tumors in children: how long does it take to establish the diagnosis? Childs Nerv Syst 2007;23(8):887-890.

16. Molineus A, Boxberger N, Redlich A, et al. Time to diagnosis of brain tumors in children: a single-centre experience. Pediatr Int 2013;55(3):305-309

17. Santi M, Kadom N, Vezina G, et al. Undiagnosed medulloblastoma presenting as fatal hemorrhage in a 14year-old boy: case report and review of the literature. Childs Nerv Syst 2007;23(7):799-80

18. Estelles LI,Charriel PB,Nieto AC.Medulloblastoma: Improved survival in recent decades. Unicentric experience.An Pediatr (barc)2017;1:4-10

19. Sarnecki J, Zdun M, Astowska M ,et al. Imaging features of medulloblastoma in children.Europian Socity of radiology.Congress Poster no:C1789.2017.www.myESR.org

20. Koral K, Gargan L and Bowers DC (2008): Imaging characteristics of atypical teratoid-rhabdoid tumor in children compared with medulloblastoma. AJR Am J Roentgenol.2008; 190:809-814.

21. Nastro A, Consiglio Buonocore $M$, Cicala D et al. Imaging of Medulloblastoma In: Özek MM, Cinalli G, Maixner W, Sainte-Rose C (eds.). Posterior Fossa Tumors in Children. DOI 10.1007/978-3-319-11274-9_15, Springer International Publishing, Switzerland, 2015;287-312.

22. Raybaud C, Barkovich AJ. Intracranial, Orbital, and Neck Masses of Childhood. In: AJ Barkovich, Raybaud C (eds.) Pediatric Neuroimaging, 5th edition, Lippincott Williams \& Wilkins 2012;637-807.

23. Fouladi M, Gajjar A, Boyett JM, Walter AW, Thompson SJ, Merchant TE, et al. Comparison of CSF cytology and spinal magnetic resonance imaging in the detection of leptomeningeal disease in pediatric medulloblastoma or primitive neuroectodermal tumor. J Clin Oncol 1999;17:3234-7

24. Nalita N, Ratanalert S, Kanjanapradit K, Chotsampancharoen T, Tunthanathip T. Survival and Prognostic Factors in Pediatric Patients with Medulloblastoma in Southern Thailand. Journal of Pediatric Neurosciences 2018; $13: 2$.

25. Chatty EM, Earle KM. Medulloblastoma. A report of 201 cases with emphasis on the relationship of histologic variants to survival. Cancer 1971;28:977 83. 
26. Kumar LP, Ahmed SF, Deepa J, Moinca I, Suresh P, Naidu KVJR. Medulloblastoma: A common pediatric tumor: Prognostic factors and predictors of outcome. Asian Journal of Neurosurgery 2015;10:1

27. Lee M, Wisoff $\mathrm{JH}$, Abbott R, et al. Management of hydrocephalus in children with medulloblastoma: prognostic factors for shunting. Pediatr Neurosurg1994; 20(4):240-247

28. Tomita T. Medulloblastomas. In: Youmans JR, editor. Neurological Surgery. Vol. 4;1996. p. 257092

29. Muzumdar D, Kumar R, Goel N, et al. Medulloblastoma in childhood-King Edward Memorial hospital surgical experience and review: comparative analysis of the case series of 365 patients. J Pediatr Neurosci 2011;6: S78-S85.

30. Rajagopal R, Abd-Ghafar S, Ganesan D, et al. Challenges of treating childhood medulloblastoma in a country with limited resources: 20 years of experience at a single tertiary center in Malaysia. J Glob Oncol 2017;3(2):143-156.

31. Njuguna F, Mostert S, Slot A. Abandonment of childhood cancer treatment in Western Kenya. Archives of Disease in Childhood 2014;99:7

32. Gajjar AJ, Robinson GW. Medulloblastoma-translating discoveries from the bench to the bedside. Nat Rev Clin Oncol 2014;11(12):714-22 